\title{
"Instructing" the Cruxes of Language Errors: Diagnosing the EFL Students' Significant Translation Errors
}

\author{
Yohannes Telaumbanua ${ }^{1 \& 2}$ \\ ${ }^{1}$ Department of English, Politeknik Negeri Padang, Indonesia \\ ${ }^{2}$ PhD student of PPs Program Doktor Ilmu Pendidikan Universitas Negeri Padang Padang, West Sumatra Province, \\ Indonesia \\ Correspondence: Yohannes Telaumbanua, PhD student of PPs Program Doktor Ilmu Pendidikan Universitas \\ Negeri Padang Padang, West Sumatra Province, Indonesia. E-mail: yohannespnp@yahoo.com
}

Received: May 20, 2019 Accepted: June 24, 2019 Online Published: August 26, 2019

doi:10.5539/ijel.v9n5p138 URL: https://doi.org/10.5539/ijel.v9n5p138

\begin{abstract}
The study follows growing the author's concern over the EFL students' significant translation errors although a number of researches in the field of Error Analysis showed the equivalent/unchanged results, namely, MT and TL interferences were the major causes of the EFL students' Writing and Translation errors. EFL students keep making errors. On the basis of the facts, the study aims at specifically instructing the cruxes of the errors, diagnosing the students' errors and observing whether or not significant improvements were found after instructing the errors. This study entailed the use of a qualitative method design. The purposive sampling and typical sample technique were ways of selecting the population and sample. Observation and unstructured interviews were techniques of collecting the data while the 1973 Corder's clinical elicitation; and Miles and Huberman's flow model were techniques of analysing the data. The results of the study showed that the significant translation errors made by the 2nd-year ED class II-A students before instructing the cruxes of errors were heavily centred on MT causes, TL interferences, and Communication Strategy of Holistic strategy of Approximation and Analytical strategy of Circumlocution-based errors. The total number of these errors was 1,948. In contrast, after instructing them, it significantly decreased to 636. The decrease in the number of errors in the students' translation positively signified that the instruction of the cruxes of the errors could deduct students' critical English language issues from making errors. The instruction in the cruxes of the errors effectively mitigates the significant effects of the MT and TL interferences, and Communication strategy-based errors; significantly improves the students' knowledge of the cruxes of the LLU errors in Translation, as well as qualifies the outputs of their Indonesian-English translation.
\end{abstract}

Keywords: instructing, Cruxes of Errors, diagnosing, EFL students' significant translation errors

\section{Introduction}

Why instructing the Cruxes of Errors in the Translation class? The bases from which the proposal or the idea of "Instructing" the Cruxes of Errors: Diagnosing the EFL Students' Significant Translation Errors strongly stood on a scientific study or theoretical analysis, the results of the preliminary observations and the researches' analyses. The followings were the details. Firstly, the linguists and the ELT experts explain, "translating formal and informal letters, business letters, essays, reports, academic papers, etc from the Source Language (SL) into the Target Language (TL) is a complicated scientific activity or process of changing from one form to another. It is said "complicated" because a translator does not only think of discovering the meaning and directly expressing it but also must be capable of understanding and being aware of the Language and Linguistic Levels, lexicons, Short terms, the contexts, etc of the TL. Besides, a translator is expected to be more (sensitive) aware of the basic cruxes of the causes of the errors toward the texts translated (Bussmann, 1996; Spillner, 1991). The understanding and awareness (sensitivity) essentially aim at helping a translator to maintain the errors free, accuracy, clearness, naturalness, etc of the translation itself (Bell, 1991; Larson, 1984). Likewise, majority of the Indonesian students, who have learnt and gotten involved in the translation services, have long thought of, experienced, and even realised that the stated targeted knowledge is the major problems that always colour the processes of translation.

Secondly, English Department (ED) students are often asked for help to translate or provide translation services. However, most of the translations were extremely disappointing and displeasing. They told the author that the 
clients - the users of translation services - strongly argued over the results of the translation after being reviewed. The readers along with the language reviewers critically commented on the cases of language form, functions, and substance (language and linguistic levels), wording, lexical, discourse (interlingual causes) and grammatical errors (target language causes), communication strategy-based, induced, compound and ambiguous errors. Principally, they frequently transfer/borrow (ignorance) SL as substitutes into the TL along with repeatedly avoid using difficult words or structures. Unfortunately, they could not explain when the author asked them about what the reviewers commented on in that translation. They did not understand the sources of the errors in their translations and this is certainly awfully dangerous if these errors are just ignored and avoided. Thirdly, similarly, when the author did his preliminary observations of the students' translated texts, it showed that the students' first/native language (L1) or the mother tongue intervention; their ignorance and avoidance of the TL forms on any levels and of many classes; their communication strategy used such as holistic strategy of approximation to predict, assimilate or equate the meaning of the lexicons; their use of the indirect ways of expressing something (analytical strategy-circumlocution) were the deviant factors affecting the translations (James, 2013; 1998).

Fourthly, to this day, in the last two decades of the 21 st-century, there have been significantly growing researches' interest in analysing, investigating, and reviewing the Errors in the EFL learners' Paragraph Writing, Writing, Essay, Translation, and Children's Literature Translation Project (Kurniawan, 2018; Chelli, 2014; Kaweera, 2013; Mungungu, 2010; Al-Khresheh, 2010; Sattayatham \& Ratanapinyowong, 2008; Sattayatham \& Honsa, 2007; Sereebenjapol, 2003). The research findings showed the equivalent and unchanged results, namely, the Interlingual and Intralingual Interferences were the major sources of their research participants' Writing and Translation errors. Nonetheless, the results of these researches have not had direct and straight effects on students' knowledge of Errors in Language Learning and Use (LLU). The students keep making errors when translating. Two of shreds of evidence are, first, the results of these studies have not been directly taught, learnt or discussed in the Writing and Translation classes and the second one is that the students have not gotten into reading or accessing the results of these researches yet. As a result, they do not understand, recognise (identify) and even be fully aware of the sources of the errors when translating which will negatively affect the translation. These reasons, therefore, drove the author to come to a decision to "specifically instruct" the theoretical Cruxes of Errors in the Translation Classes in the Indonesian-English Translation Context.

The purposes of this research are to "specifically instruct" the Cruxes of Errors for the 2nd-year ED students; to assist the students to recognise, explore, analyse, and correct their translation errors; to facilitate the students to deduct their critical Translation issues from making errors affecting the outputs of their translation; to diagnose the students' Translation errors; to qualify the students translations; and to pinpoint the qualitative effects of instructing the Cruxes of Errors on the students' Indonesian-English translation. The proposed research questions were (1) What significant errors were made by the 2nd-year ED students when translating the Indonesian texts into English? (2) Were there significant improvements after instructing the Cruxes of Errors on the 2nd-year ED students' translation?

How significant is the instructing of the Cruxes of Errors in the Translation classes? The applied significances of instructing these categories of language errors for the EFL students majoring in Translation are, firstly, the students theoretically understand the basic Cruxes of Errors in translation which have not been so far the EFL teacher's special concern of instructing them. Secondly, the instructing helps re-establish the students' micro linguistic-grammatical features of language whose methodical disparity on all levels of its structures of grammar, syntax, lexicology, morphology, semantics, etc. Thirdly, it guides them to learn practical ways of deeply exploring and analysing the errors. Fourthly, it smoothes the students' progress of being more capable of recognising, naming, and examining the exact characters of the translation problems. Fifthly, it provides "the linguistic corrective feedback as a cornerstone of solving or explaining the language and linguistic level of errors." Sixthly, it raises the students' errors sensitivity and awareness about the texts translated (Dodigovic, 2005). Lastly, it grants the students' knowledge of being capable of being self-errors predictors-correctors or evaluators (Pawlak, 2012) of what they have translated from Indonesian into English. As this paper is, for that reason, a research article of specifically instructing the Cruxes of Errors in the Translation class, the author briefly explains the fundamental Cruxes of Errors used in Translation. Here are the details.

\section{Cruxes of Errors in Llu: Theoretical Reviews}

\subsection{Mother Tongue (MT) Interference: Interlingual Causes (Inter-C)}

Theoretically, the language and or the linguistic terms, which are always clung to the MT interference, are the first language (L1) influence, interlingual interference, negative transfer, transfer or interference errors, negative 
transference of L1, negative interference of L1, and cross-linguistic interference (Sari, 2016, Kaweera, 2013; Shekhzadeh \& Gheichi, 2011; James, 1998; Touchie, 1986). The interference of these terms towards the processes of translation from the SL into the TL, according to the linguists and ELT scholars (James, 1989) occurs when "the items, words, or structures in the foreign language (FL) manifest some degree of difference from, and some degree of similarity with the equivalent items or structures in the translator's L1 (James, 1989)." For example, "Aku barusan memotong rambut, janggut, cambang, dan kumisku" was translated into English, "I just cut my hair, beard and sideburns, my moustache (which can be corrected, I just got/had a haircut and shaved beard, sideburns, and moustache)." The clear evidence of the interlingual causes of this translation was when the ED students directly transferred their dialect features of Indonesian into English. They freely and equivalently translated all the three elements from Indonesian into English. They have not been fully aware of and sensitive to the differences in the context of similarity between Indonesian and English's items, words, and structures.

What are the interlingual causes of the Translation? The misconstrued translation above was theoretically known as "ignorance (Ig)" as the translator frequently transfers/borrows her/his MT or SL as substitutes or surrogates into the TL for example, "Let us * climb a *pray ( a prayer) $(\sqrt{ }$ pray) *to $(\sqrt{ }$ for $)$ the victims of the terrible disaster of Tsunami in Palu, South Sulawesi." repeatedly avoids using difficult structures (avoidance (Av)) such as "this was my school. I studied here for 3 years," instead of "this is my school where I studied for 3 years." The L2 or FL ignorance and avoidance are, first, outwardly comes from the translator's knowledge of "Parameter Setting (PS).” The knowledge of PS is the primary L1 negative interference of misconstruing the translation. The idea of PS, which was first proposed by the Noam Chomsky in his Universal Grammar (UG) theory, elucidated that all humans acquire the same core grammar. Nonetheless, grammars superficially differ depending on which the language a particular child is exposed to (Brown \& Miller, 2013). The PS lies in the Cruxes of the unmarked numbers (Um) or unmarkedness of pidgin and the marked numbers or markedness (M). The pidgin (unmarked number) features, portraying the early child language, the simple codes, the limited vocabulary, and incomplete grammar and being often drawn from several languages, misconstrue the translation. Pidginization is identified in the translation when the translator mixes, reduces, and simplifies the language and this eventually leads to a pidgin (a pidgin is a simple form of a language which speakers of different language use to communicate. Pidgin is not anyone's first language). The same processes are often found in imperfect adult foreign/second language learning and translation (Brown \& Miller, 2013; Muysken \& Smith, 2008). The marked numbers (markedness), in contrast, are normally distorted by the FL students/translator's cross-linguistic interferences of (negative interference of L1) phonology, context-based lexis, morphology, syntax, lexico-semantics (Grammatical and Lexical Collocations and Semantic Sense Relation), stylistics, discourse analysis, orthography (Kaweera, 2013; Shekhzadeh \& Gheichi, 2011). The marked member of each pair is, according to James (1998), more uncommon, more specialized, more complex, more focused and more constrained than the unmarked (see pidgin). The indications are that the marked option will be harder to learn since it is more complex, rare, special, and constrained.

The other crucial cruxes, which are cognate with translation, are, firstly, linguistic context. This context, which can be explored from three aspects of deitic, co-text and collocations, refers within the discourse analysis, namely, the relationship between words, phrases, sentences and even paragraphs. Let us take the word "bachelor" as an example. It is rather difficult to understand the exact meaning of the sentence, "she is a bachelor" without linguistic context which makes clear the exact meaning of bachelor (Song, 2010). The second one is the context of the situation (situational context). This context consists of three aspects, namely, field referring to what is happening, to the nature of social action that is taking place (the participant is engaged). The second aspect is tenor describing who is taking part, the nature of the participants, their status and roles, the roles' (permanent/temporary) relationship among the participants, their types of speech. The last is the mode referring to what part the language is playing, what they expect the language to do for them in that situation, what is being achieved by the text, such as persuasive, expository, didactic, and the like. Collectively, the three aspects of the context of the situation are called register which is significant to a translator $(\mathrm{Hu}, 2010)$. The three aspects of the situational contexts of the ideational meaning by field, interpersonal meaning by tenor, and textual meaning by mode establish the systems of meaning in the process of communication and translation (Baker, 2009, p. 9 in Hu, 2010, p. 324). The last cultural context describing the culture, and background of language communicated in communities which influence the factors like social roles, status, sex and age (Song, 2010).

The second is the Indonesian students/translator's typological interference errors (TIE). The typological interference errors happen when the students/translators equate the SL text's linguistic typology with the TL (English) one. Theoretically, English linguistics classifies and explains its language according to its structural 
and functional features/properties dealing with the qualitative and quantitative typologies. The salient qualitative typology of English linguistics, first, covers the morphological studies of analytic, isolating, synthetic, fusional (inflected), agglutinative, polysynthetic, and oligosynthetic languages. The second qualitative typology encompasses the morphosyntactic alignments of accusative, ergative, split-ergative, austronesian, active-stative, tripartite, marked nominative, (secundative and indirective), inverse marking, syntactic and theta role language. The third is subject-verb-object (SVO) positioning. This positioning reflects the word orders of English (WO); past form (V2) and present and past participle forms; time-manner-place describing the general order of adpositional phrases in a language's sentences: "tomorrow", "by bus", "to the school" (Bickel, n.d; Comrie, Bernard, et al., 2013; Song, 2011; Gell-Mann, Murray, Ruhlen, \& Merritt; 2011). The fourth typology relates to the lexicon stressing on specific colours, cultural short items/words or other proper names like geographical, medical terms, etc. Besides, it links to the numeral describing cardinal numbers, determiners, collective numbers, or collective noun. It expresses relationships like quantity (cardinal number), sequence (ordinal number), frequency (once, twice), and a part/fraction (Hurford, 2010). Quantitative typology, in contrast, deals with the distribution and co-occurrence of structural patterns of English such as preferences (linguistic universal) correlations/linguistic convergence (Moravcsik, 2013).

The third L2/FL ignorance misconstruing the translation is "intrusive interference (II)." James (1998) explains, "If translator judges an L1 form to be sufficiently unmarked and transferable, s/he will transfer it. Whether the transfer is successful ("positive transfer") or calamitous ("negative transfer") depends on the chance isomorphism (similarity in forms) of L1 and L2/FL at the structure in question, or on their historical cognateness/relatedness or their areal affinities/similarities. The word that shares its linguistic derivation with (i.e., is related to) another is, for example, the English word "father" is cognate with the German "vater (teflnet, 1998-2019)." Similarly, in pronunciation, the introduction of additional sounds in particular environments, e.g., the intrusive $r$ found in some pronunciations where there is no ' $r$ ' in the spelling and no ' $r$ ' is generally pronounced, as in law and order [law[r] and order], Where there is an ' $r$ ' in the spelling and it is pronounced, this is known as a linking $\mathrm{r}$, as in rear end [rea[r]end] (Brown \& Miller, 2013). In 1962, the Polish linguist $\mathrm{J}$. Kury-lowicz used "Isomorphism" to show the structural analogies between phonics and semantic units, for example, the syllable, and the sentence. Both units are hierarchical structures with a central, obligatory component. The syllable is associated with vowels or consonants whereas; the sentence is linked to SVO and other parts of the sentence. Intrusive interference affects someone in a way that annoys and makes him/her feel uncomfortable. Furthermore, if the translator decides not to transfer from L1, but s/he keeps quiet instead, ignores, or avoids it, it still misconstrues the outputs of the translation or produces an unnatural sense of the translations. This last error is so-called inhibitive interference or In-I (James, 1998).

\subsection{Target Language (TL) Interference: Intralingual Causes (Intra-C)}

In addition to the previous discussion of the MT interference, FL students/translators theoretically have not been free from making errors of the TL. James (1998) explains, "Learning strategies are used for code-breaking while communication strategies are encoding and decoding strategies." Both strategies can be sources of errors or TL Interference. Here are the details. False analogy (FA) or cross-association (CA) (George, 1972) is the first FL students/translators' TL interference. The students tend to incorrectly assume that the B similarly behaves like A, for example, A: "He bought a car" where the car has its own plural form (N-Count) "cars..", Likewise, they analogise that B: "goose" has the same plural form as "cars." Gooses are pluralised just like the process of

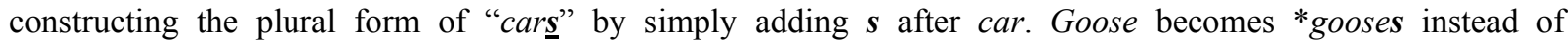
grammatically understanding that goose is the irregular plural noun of geese (Azar, 1989).

Secondly, the false concept often happens when the $\underline{\underline{s}}$ - is pluralised form of $\boldsymbol{i}$ as in "they are carnivorous plants

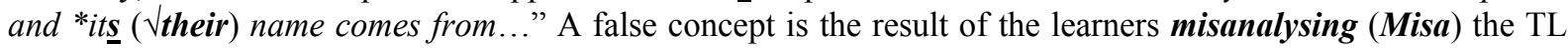
and it normally occurs when the FL students base their hypothesis on their native language (James, 1998). Thirdly, the example of, "We do not know where *does she live ( $\sqrt{\text { she lives }})$ " is seen in the deviant order of "subject" and "be." The FL students tend to apply only two components of the interrogative formation rule. They have selected and fronted a wh-element (rule components 1 and 2), but have omitted to "invert the subject and verb (James, 1998)." They incompletely apply the rules, for example, does, did, do, will, should, etc, which are used in questions, and can differentiate them in noun clauses. This TL interference is called incomplete rule application (IRA).

Fourthly, In English usage, redundancy (R) is usually defined as the use of two or more words that express the same thing, but it is sometimes used to refer to any expression in which a modifier's meaning is contained in the word it modifies for examples: early beginnings, merge together (Grammarist, n.d). Redundancies, according to Nordquist (2019), are words that overflow one's ideas and the clutter of one's ideas must be cut to grammatically, 
lexically, and contextually establish the clear connections, information, ideas, and intentions in writing and speaking/speech (Wit \& Gillette, 1999). These sentences, "they were asked to join together; the machines are manually by hand; they write their past experiences are redundant as joining together similarly expresses the objects that join can only do so together; the manually means by hand; and past experiences are experiences in the past (Grammarist, n.d). Redundancy, in contrast, linguistically enhances comprehensibility, resolves ambiguity, isolates a feature, contrasts elements, emphasise/intensify and creates poetic effects (Wit \& Gillette, 1999).

Fifthly, overlooking cooccurrence restrictions (OCR) is the FL students' ignorance of the fact that, for example, "I regretted "to tell (Vtelling) her my secret" the verb "regretted" selects a gerundial complement. Another example is "people in big cities live *more *quick ( $\checkmark$ faster $)$ than those in villages." The errors here are first the FL students wrongly assume that quick is synonymous with fast. The second is people in big cities are compared with those in villages and the quality is only one 'fast,' it is used in its comparative form 'faster,' or 'Jane is

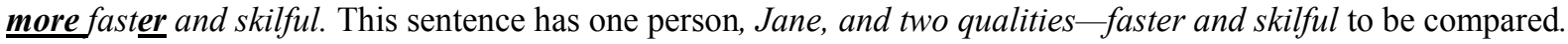
One is comparing these two qualities to say that she has one quality more than others, "fast" is more than "skilful." In this case, it does not use the original comparative form with ' $r$ ' or 'er' although the adjective has the form but use 'more' before the word in its form. That is to say, that the adjective word 'fast' has 'faster' but it is not used, as it is not comparing Jane with anybody else. It compares the two qualities of Jane has in her (Kumar, 2009). Grammatical collocations (good $*_{\text {in }} / V_{\text {at }}$; compare $*_{\text {in }} / V_{\text {to }} / \widehat{V}_{\text {with }}$ ) and lexical collocations $($ *make/ $\sqrt{\text { do business) }}$ are the FL students' ignorance of overlooking (the TL) co-occurrence restrictions (James, 1998).

As the sixth TL interference, hypercorrection (Hy) or monitor overuse happens when FL students/translators misapplied or over applied the L2/FL output as an attempt to correct the usage of English consistently. Nichol (2019) identifies 10 types of hypercorrection in English usages, they are, 'A number of' followed by a 'Singular Verb', ' $A s$ ' in place of 'Like', Double Adverbs, Foreign Articles Preceding Foreign Terms, ' $I$ ' substitutes for the object of ' $M e$ ', Latin Plurals formed incorrectly, Prepositions prevented from Ending a Sentence, Unsplit Compound Verbs, Unsplit Infinitives, Whom in place of Who.

Hypercorrection in sociolinguistic and applied linguistic studies is non-formal use of English producing over-application of perceived rules of English Speech Sounds, words which can be put together in order to make sentences, and words which are constructed with stems, prefixes, and suffixes. The EFL students believe as if the hypercorrection produced is grammatically correct and accepted or preferable (Wilson, 1993; William, 1972). Linguistically, hypercorrection appears one the EFL the real or unreal sentence structures applied in inappropriate contexts and this can be averted if the EFL students copy follows his/her natural speech instinct (Menner, 1973). Personal pronouns subject positioned (Huddleston \& Pullum, 2005); H-adding, e.g., 'have' become 'ave' (Graham, 2019); Hyperforeignism coming up from the speakers/writers/translators misidentifying the circulation of an example found in loanwords and extending it to the other surroundings are frequently labelled as the common causes of hypercorrection in English. The effect of this process does not replicate the rules of either language (Wells, 1982); and English as a Second/Foreign Language where Indonesian speakers of English are prone to being cognate with the same words from their native language to TL such as 'adaptation' (English) becomes in Indonesian 'adaptasi' (Huebner \& Ferguson, 1991).

As the converse of the incomplete rule application, this last TL interference, overgeneralization (OG) or system-simplification (SS) leads to the overindulgence of one member of a set of forms and the underuse of others in the set as in "I saw the girl *that $(\sqrt{ }$ who $)$ closed the window." This example is the generalization of the adjective clause 'that'. The FL students/translators use that to the exclusion of ' who'. James (1998) explicates, "Similar overgeneralization to one of two TL alternatives happens with other/another, much/many, none/neither, some/any and many more such 'confusables'. It is not restricted to lexical pairs of course. System options such as tense-marking are also susceptible."

\subsection{Communication Strategy (CS)-Based Error}

Holistic strategy (Hs)-based CS refers to the FL students/translators assuming that X is close to Y. Because of it, they try to look for similarity, equation, a synonym for the word of or substitute the cognate, e.g., *credibility for the intended $V_{\text {truth. James }}(1998)$ elucidated, "The most general term for this is approximation (A). They guess a number of words that are "not exact" but "close." It takes on a number of forms, the first of which is to use a near synonym. Alternatively, one can use a superordinate term like *fruits for $\sqrt{ }$ blackberries. A third option is to

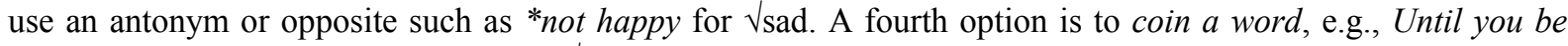
unconscious to lose your *sensities ( $\sqrt{\text { senses}) . " ~ I n ~ C o n t r a s t, ~ a n a l y t i c ~ s t r a t e g i e s ~(A s) ~ i s ~ a ~ C S-b a s e d ~ e r r o r ~}$ 
influencing the FL students/translators to look for an indirect way (by illusion) of saying something rather than direct reference. The interference is known as circumlocution (Cir) where the students identify one or more criterial attributes of the referent, e.g. "Economical with the truth" is a circumlocution for "lying" and mention it as an attempt to refer to the entity in question (James, 1998).

\subsection{Induced Error (IE)}

Theoretically, IE mostly happens in a classroom situation. James (1998) explains, "The students are the result of being misled by the ways in which the teacher gives definitions, examples, explanations and arrange practice opportunities." The other sources of IE are material IE (MIE), teacher-talk IE (TTIE), exercise-based IE (EBIE), error-induced by pedagogical priorities (E-IPP): accuracy, fluency or idiomaticity, and look-up errors $(\boldsymbol{L U E})$. James said, "The students already knew when the teacher explained the verb worship 'as a general word for pray and grammatically paired with to which they assumed also applied to worship. The result was worshipping *to God (the correct one is worshipping God). This is a clear case of cross-association (CA) or overgeneralization $(O G)$."

\subsection{Compound Errors (CE) and Ambiguous Errors (AE)}

James (1998) elucidates, “A compound error arouses more than one cause operating either simultaneously or cumulatively, for example, consider the error in My watch does not *walk well. It is plausible to trace this to a lexical (not * walk but $\sqrt{\text { work}}$ ) and a phonological ( $\sqrt{\text { work }}$ is mispronounced as in UK/wo:k/ US /wa:k/) causes and these confusables to the FL students. Ambiguous Errors, in contrast, arouses when the students mispronounced, for examples, "having *watch, "having *to watch, or "Vhaving watched that movie before, I did not want to go again." Having + past participle gives the meaning not only of "because" but also of "before." Having + past participle expresses cause and effect relationship modifying phrases (Azar, 1989). The other examples, when a student involved obstruent devoicing, were "the *standart $/ \sqrt{s t a n d a r} \boldsymbol{d}$ " of living is USA is expensive...; we could

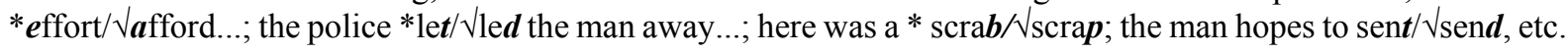
Both are cognate with the lexical and phonological causes/errors of the FL students (James, 1998).

\section{Method}

The research entailed the use of a qualitative method design to explicate more detailed and wide-ranging images of the problems under investigation and to acquire the expected learning outputs (Bell \& Aldridge, 2014). The selection of this design was in line with the objectives of this research. Besides, it led the author to explore the open questions about instructing the "errors" rather than tested theoretically derived (deductive) hypotheses; and provided the detailed descriptions capturing the students' personal perspectives, experiences, or knowledge (data) after instructing/learning the Theory of "Errors." More importantly, this design practically provided an understanding of the author of what the instructing of errors meant to the students (Fraenkel \& Wallen, 2009).

Politeknik Negeri Padang was the locus of conducting the research. This research started on the 4th of January 2019 and ended 10th of May 2019. The population was all 2nd year ED students numbering 59. The sample (participants) who were being involved was, on the other hand, Class II-A numbering 30 students. Furthermore, the purposive sampling or known as judgmental, selective, or subjective sampling is a non-probability sample was selected based on its characteristics of the population. Whereas, the typical sampling technique (type) was used because the chosen sample was considered or judged typical or representative of that which were being investigated. The author selected the 2nd year ED class II-A students a sample because they yielded the best understanding of what the author was studying (Fraenkel \& Wallen, 2009; Crossman \& Cole, 2018). The corpora were the 2nd year ED class II-A students' Indonesian-English Translation texts.

The observations of selected participants, unstructured interview and the diagnosis, analysis or examination of the texts translated from the Indonesian into English were the techniques exercised in collecting the data. In this observation, the researchers took on the roles of complete participants in that class, his identities were not known to the 2nd year ED class II-A students being taught. The researcher disguised his identity and acted just like the other college teachers. The author interacted with them naturally; totally participate in the instructional activities and processes of the students being studied, but also made it clear that the author was doing research. This was covert participant observation. Field notes, field diary, or field jottings (quick note) were the instruments of collecting the data (Fraenkel \& Wallen, 2009).

Data analysis involved analyzing and synthesizing the information the author obtained from the observations and diagnosis of the texts translated from Indonesian into English into coherent descriptions of what he observed or otherwise discovered. The data analysis, however, relied on the description of the students' translation errors. The interpretations and conclusion were made continuously throughout the course of the study which was 
integrated with the stages in the research process (Fraenkel \& Wallen, 2009). The stages of analyzing the data were first collecting the samples of students' translation errors, identifying, describing, and explaining the errors. The adopted steps were originally from the "1973 Corder's clinical elicitation" requiring the participants to produce the data by means of translating the Indonesian texts into English. The second was data reduction. The author sharpened, classified, organized, and removed the unnecessary data so that the conclusion could be drawn. The reduction did not need to be interpreted as quantification of data. The second was the presentation of data. This phase displayed the deducted data and categorized them into the forms of the narrative texts in the form of field notes or graphs based on the criteria set. The last was the drawing conclusion. This last sequence of data analysis was a fixed and final interpretation of the study and considered as the result of the analysis that could be used to take action (Miles, M. B. \& Huberman, A. M. Saldaña, J, 1994).

\section{Results and Discussions}

\subsection{Results}

Briefly, the pie chart below showed the Diagnostic Results of the Students' Significant Translation Errors before and after instructing the Cruxes of Errors. Before instructing them, the total number of errors in the students' translation significantly increased to 1,948. The numbers of each type of errors-MT, TL and CS-based errors - were 1,255,589, and 104 respectively. In contrast, after instructing them, the overall errors dramatically dwindled to 636 where the numbers of each type of errors-MT, TL and CS-based errors-were 473,150, and 13 respectively. It could be clearly seen that the discrepancies between the total numbers of errors before and after instructing the Cruxes of Errors signified that the instructing of the Cruxes of Errors in the Translation class is effective and positively affected the outputs of the students' translation.

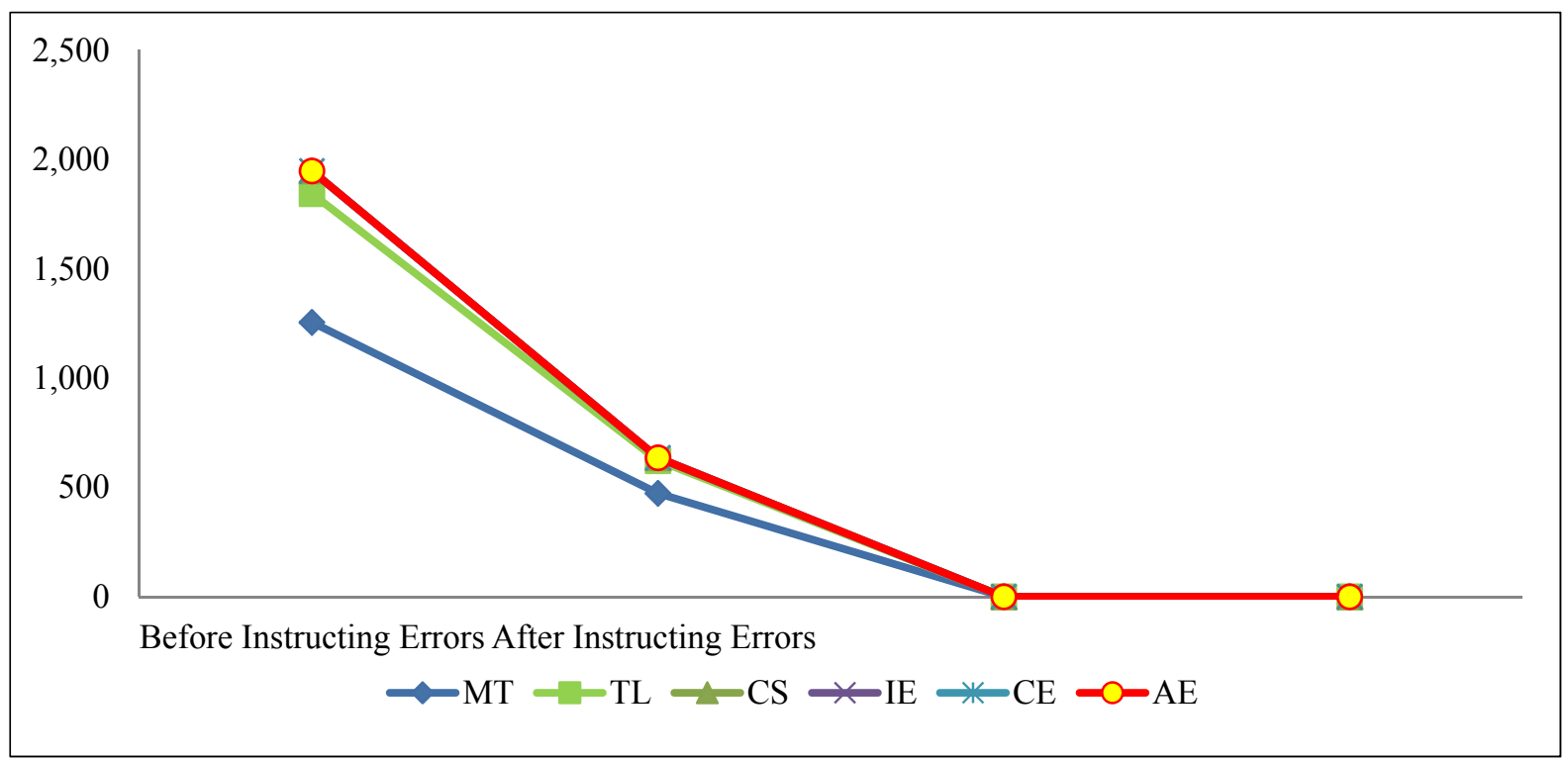

Figure 1. Diagnostic results of the students' significant translation errors before and after instructing errors

\subsection{Discussions}

It was undeniable that the decision to "instruct the Theory of Errors" in the Translation class was precisely correct because it deducted the students from ceaselessly making errors and encouraged them to naturally sound and qualify the outputs of their translations. To save the author lots of pages, the research findings and the discussions were displayed and elucidated simultaneously in accordance with the sequences of the research questions. At an early stage of the research, the author prepared the students to translate the Indonesian texts into English without introducing or instructing them to the Cruxes of the Errors in LLU in Translation. They were given three days to translate the texts and the results of the diagnoses were as follows. 
ijel.ccsenet.org International Journal of English Linguistics $\quad$ Vol. 9, No. 5; 2019

Table 1. Diagnostic results of the students' significant translation errors before instructing errors $(n=30)$

\begin{tabular}{|c|c|c|c|c|c|c|c|c|}
\hline \multicolumn{9}{|c|}{ number of occurrences of Errors in the Students' translation } \\
\hline \multirow[t]{3}{*}{ MT } & Ig & Av & PS & & TIE & II & In-I & Total \\
\hline & & & Um & $\mathbf{M}$ & & & & \\
\hline & 345 & 273 & - & 544 & 93 & - & - & 1,255 \\
\hline \multirow[t]{2}{*}{ TL } & FA/CA & Misa & IRA & $\mathbf{R}$ & OCR & Hy & OG/SS & 589 \\
\hline & 63 & 35 & 75 & 209 & 5 & 15 & 187 & \\
\hline \multirow[t]{2}{*}{ CS } & Hs - A & As-Cir & - & - & - & - & - & 104 \\
\hline & 93 & 11 & - & - & - & - & - & \\
\hline \multirow[t]{2}{*}{ IE } & MIE & TTIE & EBIE & E-IPP & LUE & - & - & 00 \\
\hline & - & - & - & - & - & - & - & \\
\hline $\mathbf{C E}$ & \multicolumn{7}{|c|}{ no lexical and phonological causes found } & 00 \\
\hline $\mathbf{A E}$ & \multicolumn{7}{|c|}{ no lexical and phonological causes found } & 00 \\
\hline \multicolumn{8}{|c|}{ The total number of errors } & 1,948 \\
\hline
\end{tabular}

Table 1 illustrated the total number of errors made by the 2nd-year ED Class II-A students significantly increased reaching 1.948. The total number of these errors was quite alarming and could distort the outputs of the translation if the Cruxes of Errors in LLU in Translation are not instructed/introduced earlier before the translation activities or processes take place. Answering to the first research question, MT interference-whose total number of occurrences of Errors was 1,255-was the most significant errors made by the students when translating the Indonesian texts into English. The details were as follows. Firstly, on the diagnosis-based category of Interlingual causes; the number of errors caused by the students' Ig was 345 meaning that each student, with a sample size of 30 research participants, produced 11.5 errors. The digit showed that the 2nd-year ED Class II-A students frequently borrowed or transferred Indonesian as surrogates into English. Two of the many examples of the sentences was, "saya bawa mobil kemarin" and was then translated into English as in "I *bring/ $\sqrt{\text { drove * }}$ "car/ $/$ a car yesterday." Another one was "doktor menyuruh pasien untuk berhenti minum rokok" was then translated into English as in "the doctor *told $/ \sqrt{ }$ had *patients $/ \sqrt{ }$ the *patients to stop *drinking cigarettes $/ /$ stop smoking."

Hereinafter, the students' attempts to avoid using difficult English structures were the second errors frequently made. The number of errors caused by the students' Av was 273 indicating that each produced 9.1 errors. The PS of $\mathrm{M}$ - whose total number reached 544-was the third most significant errors made by the students. The errors were extremely influenced by the students' cross-linguistic interferences of lexico-semantics (Grammatical collocations, for examples, "account *to/ $/$ for, accuse (somebody) *for/ $/$ of" and Lexical Collocations, for examples, "*bargain/Voffer opposition, *make/Ncommit treason" and Semantic Sense Relations such as "a bird

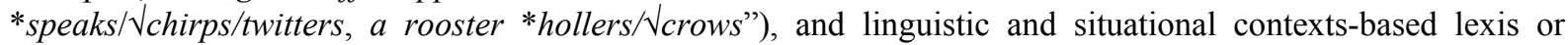
vocabulary linking to the formal registers and meaning, e.g., composite in fiction mean various combination, and composite in engineering means material. The 30 students produced 193 incorrect uses of lexical collocations, or each of the students produced 6.43 errors; 147 incorrect uses of grammatical collocations or every student produced 4.9 errors; 87 incorrect uses of semantic sense relations or each produced 2.9 errors, and 117 incorrect uses of registers or each of them produced 3.9 errors. The last was the students' TIE was 93 signifying that each student produced 3.1 errors in SVO/WO positioning, past and past participle forms, and time-manner-place describing the general order of adpositional phrases of English sentences, e.g., "KFC [is] the children eat at the Plaza yesterday." It was, in contrast, found no the II and In-I misconstruing the translation.

Secondly, in the diagnosis-based category of Intralingual cause (TL interferences); the students were still slipping into making errors. The students' sources of TL errors were, first, the FA/CA numbering 63 where every student produced 2.1 errors. These errors were produced because they analogised that the processes of constructing the regular (e.g., the plural form of fan is fans) and irregular plural nouns (e.g., the plural form of loaf is *loafs $/ \sqrt{ }$ loaves) were similar or those special expressions were, for examples: the patients have difficulty *to take (Vtaking)

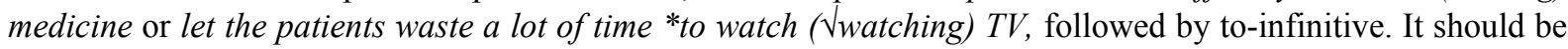
followed by the -ING form of a verb. Misa, whose errors numbered 35, was the second TL errors made. Each student produced 1.2 errors in misanalysing the sentences. The errors were made when the $\underline{\underline{s}}$ - was considered as a pluralised form of it as in the machines had been maintained and some of $*$ its ( $\downarrow$ their) parts have been replaced. The third TL errors made were IRA when they incompletely applied the rules of Noun Clauses, for example. The number of errors in incorrectly using the rules was 75 where each produced 2.5 errors. The fourth was the students' $\mathrm{R}$ such as "the end/final results, mixed together, etc" significantly increased numbering 209 where each of them produced 6.96 errors. OCR, the incorrect uses of gerunds and infinitives, and Hy, the incorrect uses of double adverbs, a number of using a singular verb, etc, were the fifth and sixth TL causes made by the students. The 
numbers of these two errors were 5 and 15 while each of the students produced 0.16 and 0.5 errors respectively. The last was the students' OG/SS. The number of the errors was 187 where each student produced 6.23 times of over-generalising the adjectives clauses, e.g., the man *that/ $/$ who tried to interrupt me was my brother's colleague). The students were also dazed to use correct determiners such as "both/both of, all/all of, each/every, little/few, other/another, much/many, none/neither, some/any, etc, for example: have you got *some/Vany books? Both of ( $\sqrt{\text { these }})$ *restaurants are very good." These determiners are similar in meaning but not exactly the same in use and these make them perplexed.

Intralingually, the EFL students and or the novice translators' monolingual knowledge significantly "instils a sense of Indonesianization in the Indonesian-English Translation" and this is one of the essential/primary raisons d'être behind the translation errors. A sense of Indonesianization is defined as the EFL students and or the novice translators' viscous perspective of comprehensively thinking Indonesian when translating the Indonesian texts into English. Such a perspective is called as the "English competence and performance-based Translation errors where the EFL students and the novice translators are 'less sensitive' to the English knowledge of the language and the binding contextual-authentic uses of the English language in real-life settings." The 'insensitivity' towards the English forms (the grammatical tenets and linguistic elements of the Semantics, Syntax, Morphology, Phraseology, Lexicology, and Sociolinguistics frequently exercised across the diverse content-particular subjects/topics), English functions (the dynamic uses of the language for specific purposes to convey ideas, commune with others, and illustrate the understanding of the contents in academic settings) and other grammatical functions specific to English misconstrued the translation (Brinton \& Brinton, 2010; Huddleston, 1984; O’Dwyer, 2000).

Similarly, the EFL students and translators' ignorance and avoidance of the cruxes of the ninth English grammatical forms of Pronouns, Nouns, Verbs, Adjectives, Adverbs, Determiners, Prepositions, P-Words, Conjunctions, and Interjections; of the important parts of grammatical functions specific to English of Subjects, Predicates/Linking/connector verbs, Subject Complements of Predicate Nominative and Predicate Adjective, Object Complements as Direct and Indirect Objects, Prepositional, Adpositional and Postpositional Complements, Prepositional Phrase and Noun Phrase Modifiers, Noun Phrase Complements, Noun, Adjectives and Adverb Clauses modifiers, Appositives, Adjective Phrase Modifiers, Adjective Phrase Complements, Verb Phrase Modifiers and Complements, Tenses and their Passives Voices, Modal Auxiliaries, Operators, Adjunct, Disjunct and Conjunct Adverbials, Determinative, Particles, Infinitive Markers, Coordination, Correlating Conjunctions, Subordinates/Dependent Clauses (Brinton \& Brinton, 2010; Huddleston, 1984; O’Dwyer, 2000); of the two basic criteria of the textual knowledge of cohesion and coherence; of the functional knowledge of cultural references and figures of speech and of the sociolinguistic knowledge of registers and natural and idiomatic expressions (Bagaric \& Djigunovic, 2007) grammatically distorted the sentence-level accuracies of the Indonesian-English translation. The grammatical, textual, functional, and sociolinguistic language knowledge is the original ideas of Bachman and Palmer which were proposed in 1996. These ideas are crucial to meaningfully qualify the EFL students/translators' translation outputs.

Thirdly, in analysing the CS-based errors, the students attempted to guess or look for a similarity of the words to prevent them from repeating the same lexicons or to simplify them to translate the Indonesian texts. They kept equating a number of Lexis/vocabularies which are "not exact" but close like "principle for the intended $\sqrt{ }$ belief." The number of errors made in this Hs-A was 93 where each produced 3.1 errors. In contrast, the As-Cir, an indirect way of saying something rather than the direct ones was 11 where each of them produced $0,36 \mathrm{~s}$ as in "politicians are *specialists in deciding the state budgets." Politicians are circumlocution (an indirect way of saying) for specialists. "Specialist" is not a special technical term for a politician. It was, therefore, incorrect. Fourthly, in diagnosing the IE, the author has not had in-depth reviews of the students' errors resulting in more from the instructing materials, teacher-talks, given exercises, pedagogical priorities, and dictionary. The author believed that the developed instructional materials, the given exercises, the teacher's explanation, the pedagogical principles, and the dictionary used have been in line with the academic standards and translation cruxes. The fifth and the last types of TL interferences, $\mathrm{CE}$ and $\mathrm{AE}$, are mostly about lexical and phonological errors. These errors were not diagnosed because they were not parts of the focus of this study. In conclusion, the MT interference, the learning strategies-based and communication strategies-based errors distorted the outputs of the students' translation.

The results of the diagnosis above were primary references to the author to instruct the Cruxes of the Errors. The aims were to diagnose the significant errors made by the students and explain the significant improvements to the students' translation results. The stages of instructing the Cruxes of the Errors applied the Chamot, Barnhardt, El-Dinary and Robbins' (1999) Cognitive Academic Language Learning Approach or CALLA. Here were the stages. The first was the preparation (activate the students' prior knowledge). The students were given chance for 
45 minutes to translate the Indonesian text into English and then asked them to carefully heed the texts translated and explain the oddities, irregularities or incompatibilities found in the translation. The second was the presentation (explaining and modelling). The author introduced and explained the cruxes of errors in Translation and discusses the errors with the students. The third was the practice (prompting strategies and giving feedback). The author had the students analyse, review, and revise the translation. The students were suggested to work in pairs or groups of 3 to share ideas and help each other. When they were finished, had pairs or groups exchange their works, check, and comment on the works. The fourth was the class discussion. The pairs and or groups of 3 presented their works and explained their analysis, reviews or revisions while others were given chances to listen to the presenters and comments on. The fifth was the practice (prompting strategies and giving feedback). The author had the students to individually commence re-translating based on the critics, comments, and or suggestions provided by the teacher and other pairs and groups. The sixth was the evaluation (assessing students' translation). After having written their first translation draft, the author had them review it by referring to the Cruxes of Errors and other Cruxes of Translation.

The seventh was self-learning reflection (thinking about the Cruxes of Errors and translation). This helped them develop their knowledge of errors in LLU and other Cruxes of translation. This is a way of evaluating themselves, their ways of working, and how they learn. Thinking about their own knowledge of Errors can help them recognize any positive changes they might require to make. Reflective questions ask about (1) Strengths: What are my strengths? Am I a good translator? Can I understand well and distinguish the cruxes of the MT, TL, CS, IE, CE and AE? how qualified is my translation? (2) Weaknesses: What are my weaknesses? Are the outputs of the translation displeasing and disappointing? Do I need more knowledge and more exercises with a particular skill? (3) Skills: What skills, competencies, or knowledge do I have and what am I good at? (4) Problems: What problems are often encountered when translating? Do the problems negatively affect my translation and me? (5) Achievements: What have I translated and achieved? (6) Happiness: What makes me satisfied with the translation? (7) Solutions: What could I do to advance in these areas? (Unison, the Open University, 2019). The eighth was the expansion (support and transfer). The author had the students translate the other Indonesian texts into English; had them discuss the Cruxes of Errors and translation with their pairs/groups of 3; and had them reports what they have done at the next meeting. The last was to have the students accomplish their Final Project of Translation.

Table 2. Diagnostic results of the students' significant translation errors after instructing errors $(n=30)$

\begin{tabular}{|c|c|c|c|c|c|c|c|c|}
\hline \multicolumn{9}{|c|}{ number of occurrences of Errors in the Students' translation } \\
\hline \multirow[t]{3}{*}{ MT } & Ig & Av & PS & & TIE & II & In-I & Total \\
\hline & & & Um & $\mathbf{M}$ & & & & \\
\hline & 123 & 102 & - & 217 & 31 & - & - & 473 \\
\hline \multirow[t]{2}{*}{ TL } & FA/CA & Misa & IRA & $\mathbf{R}$ & OCR & Hy & OG/SS & 150 \\
\hline & 27 & 18 & 26 & 37 & 2 & 7 & 33 & \\
\hline \multirow[t]{2}{*}{ CS } & Hs - A & As-Cir & - & - & - & - & - & 13 \\
\hline & 10 & 3 & - & - & - & - & - & \\
\hline \multirow[t]{2}{*}{ IE } & MIE & TTIE & EBIE & E-IPP & LUE & - & - & 00 \\
\hline & - & - & - & - & - & - & - & \\
\hline $\mathbf{C E}$ & \multicolumn{7}{|c|}{ no lexical and phonological causes found } & 00 \\
\hline $\mathbf{A E}$ & \multicolumn{7}{|c|}{ no lexical and phonological causes found } & 00 \\
\hline \multicolumn{8}{|c|}{ The total number of errors } & 636 \\
\hline
\end{tabular}

Table 2 showed the total number of errors made by the 2nd ED Class II-A students significantly decreased reaching 636 . The decrease in the number of errors was quite satisfying because they have a better understanding of the cruxes of the Errors taught. As a result, the instructing directly and positively affect the outputs of the students' translation. The diagnostic results of the students' significant translation errors had answered the second research question that there were significant improvements after instructing the Cruxes of Errors in Translation class. It could be seen that the total number of occurrences of MT interferences was 473 . The details were as follows. Firstly, on the diagnosis-based category of Interlingual causes (MT); the number of errors caused by the students' Ig was 123 indicating that each produced 4.1 errors. The digit designated that the 2nd-year ED Class II-A students realized that borrowing Indonesian words/lexis as substitutes into English was not justified. The students' success in avoiding using difficult English structures was the second important point which made them able to reduce the number of Av's errors from 273 to 102 . The number, 102, signified that each of them produced 3.4 errors. Subsequently, the total number of M was, at a glance, higher but when the total number of M, 217, was 
distributed to, it was smaller than the previous ones. In cross-linguistic interferences of lexico-semantics and linguistic and situational contexts-based lexis or vocabulary linking to the specific registers and meaning, the students were capable of solving and deducting the unexpected errors in their translation. The 30 students produced 72 incorrect lexical collocations or each produced 2.4 errors; 55 incorrect grammatical collocations, or each produced 1.8 errors; 38 incorrect semantic sense relations or each produced 1.2 errors and 52 incorrect registers or each produced 1.7 errors. The last was the students' TIE was 31 designating that each produced 1.0 errors. This meant that they had a better understanding of the SVO/WO positioning, past and past participle forms, and time-manner-place describing the general order of adpositional phrases of English sentences. In contrast, it was found no the II and In-I misconstruing the translation.

Secondly, in the diagnosis-based category of the TL interferences; the students were still found to make errors but it was still in the smallest amounts. The number of students' FA/CA was 27 where each produced 0.9 (or 9 out of 30 students produced errors); Misa was 18 where each of them produced 0.6 (or 18 out of 30 students produced errors); IRA was 26 or each produced 0,8 errors (or 26 out of 30 students produced errors); $\mathrm{R}$ was 37 where each of them produced 1.2 errors; ORC and Hy were 2 and 7 or each produced 0.06 and 0.23 errors respectively and $\mathrm{OG} / \mathrm{SS}$ was 33 where each of the students produced 1.1 errors. These numbers meant that the, firstly, students have correctly analogised that the new item B does not behave like A. Secondly, did not have misconceptions in understanding, for example, the Singular personal pronoun, etc in English. Thirdly, they better understood the subject-verb inversions specifically in noun clauses. Fourthly, they prevented from repeating the same words such as mixed together, etc. Fifthly, they understood the correct uses of gerunds and infinitives; the correct uses of double adverbs, a number of using a singular verb, etc. The last was the students were not over-generalising the adjective, noun, and adverb clauses; tense marking; and other/another, much/many, none/neither, some/any, etc. Thirdly, in analysing the CS-based errors, the students avoided guessing or looking for the similarity of the words. This was seen from the number of Hs-A produced was 10 where each of them produced 0.3 and As-Cir was 3 or each produced 0.1 error or 3 out of 30 students produced errors. The fifth and the last types of TL interferences, CE and $\mathrm{AE}$, are mostly about lexical and phonological errors. These errors were not diagnosed because they were not the focuses of this study. In conclusion, it can be generally ascertained that, whatever techniques, strategies, approaches, or methods of instructing are used, the instructing of the Cruxes of Errors in the EFL classrooms can deduct the MT interference, the learning strategies-based and communication strategies-based errors in the students' translation and or language learning and use. The instructing qualifies the outputs of the students' translation.

\section{Pedagogical Implication for EFL context}

Instructing the Cruxes of Errors provides two key pedagogical implications for the Translation teachers, ELT practitioners, ELT and learning material developers, and or educators. The first is the Translation teachers can apply the cruxes of interlingual and intralingual interferences, Communication Strategy, Induced, Compound, and Ambiguous Errors as the instruments for measuring the students' learning progress, as way-outs of providing corrective feedbacks, as reviews of the developed ELT materials, the assigned exercises, and the applied language instructing methods/techniques/strategies. The instruments, corrective feedbacks (Kaweera, 2013), and others are the soft-reminders for Translation teachers to in-depth recognise and directly correct the students' translation errors. In the Indonesian-English Translation contexts and if specifically referring to the students' translation diagnoses, the Translation teacher's priorities (primary reviews and corrective feedbacks) in instructing the Cruxes of Errors are the Cruxes of Ignorance and Avoidance, Cross-Linguistic Interferences of Lexica Semantics of Grammatical Collocations, Lexical Collocations, Semantic-Sense Relations, Linguistic and Situational Contexts-based Lexis linking to the Formal Registers and Meaning. The other ones are the approximation and circumlocution.

Even though the numbers or the levels of Errors of English Grammar (see the TL interferences) are not as significant as the MT causes, the Translation teachers are asked to keep prioritizing to "review" the students' errors of Tenses, SVO (word order/subject-verb agreement), Word Forms, WH and Yes/No Questions, Nouns (regular and irregular nouns) and Pronouns, Modals Auxiliaries, Connection Ideas, Comparisons, the Passives, Count/Noun-Count Nouns and Articles, Coordinating Conjunctions, Gerunds and Infinitives, Adjective, Adverb and Noun Clauses, Connectives expressing causes and effects, contrasts, and conditions, expressing wishes, Quoted and Reported Speeches, Conditional Sentences, other uses of that-clauses, Substituting So for a that-clause, Phrasal Verbs (separable, non-separable and intransitive), Three-Word Phrasal Verbs such as "drop in on, look out for, get along with, etc," Preposition combinations such as "belong to, absent from, admire...for ..., aware of, etc." The translation teachers require, indeed, extra work in reviewing, not to instruct, the students' grammatical errors because, for examples, there are found 5 students making errors in Adjective, Adverb and Noun Clauses, 7 
students made errors in gerunds, the other 3 made errors in that-clauses and so forth. These grammatical errors are inevitable and these which frequently colour the outputs of the students' translation.

The last pedagogical implication in instructing the Cruxes of Errors for the EFL context is to arouse and ignite the students' error awareness and sensitivity. The errors found in the translation are the students' bilingual, bicultural and biliterate experiences (Kaweera, 2013) and these experiences can distort the accuracy, clearness, naturalness, etc of the translation itself. The instruction in, based on the author's experiences, the Cruxes of Errors can effectively deduct the students' attempt to frequently borrow their L1 — Indonesian — as surrogates into English and promote/encourage them to consider using difficult English structures. Hereinafter, the instructing can improve the students' knowledge and understanding of English linguistics especially in Semantics (Grammatical and Lexical Collocations, Semantic-Sense Relations) and Linguistic and Situational Contexts linking to the formal register and meaning. It also brings the students' sense that guessing (approximation) a number of words that are not exact, though they are close, is unjustified or not a good reason for doing it in the translation activities. In circumlocution (indirect way of saying something (unpleasant)), it makes them realise that identifying one or more criterial characteristics of a referent and mentions it as an attempt to refer to the entity in questions needs to be critically avoided. The better understanding of MT interferences, learning strategies-based errors (TL interferences), CS, IE, $\mathrm{CE}$, and $\mathrm{AE}$ best qualify the outputs of the students' translation.

\section{Conclusion}

In conclusion, the instruction in the Cruxes of the Errors effectively mitigates the significant effects of the Mother Tongue interferences, Learning Strategies-based (TL interferences), and Communication strategy-based errors in the 2nd-year ED students' Indonesian-English translation. The effectiveness of instructing the cruxes of the errors was clearly reflected in the results achieved by students. Both of the total numbers of the errors diagnosed indicated that the instruction could minimise the L1, L2, and other interferences and better augments the students' organizational (grammatical and textual theories) and pragmatic (functional and sociolinguistic tenets) language knowledge. Besides, the instruction has enabled them to be more capable of diagnosing (recognising, exploring, analysing, explaining, and correcting) the sources/causes of the errors they themselves made. In their "self-learning reflection," they explained that the instruction better developed their knowledge, understanding (sensitivity), and awareness of the cruxes of errors in language learning and use in particular in Translation and any positive changes they might require to make. They understood and were aware of their translation's strengths and weaknesses; the skills required; capable of diagnosing the problems; recognised what they have achieved in translation and able to think of what they are going to advance in these areas. The students' ignorance, avoidance, markedness/marked numbers, typological interference errors, false analogy, misanalysing, incomplete rule application, redundancy, overlooking cooccurrence restrictions, hypercorrection, overgeneralization, holistic strategy of approximation and analytical strategies of circumlocution were, however, the major sources of the 2nd Year ED students' significant translation errors. It is, therefore, expected to the Translation teacher to design and develop a model of teaching Translation, ELT and learning materials as well as Authentic/Performance Assessment Scoring Criteria as practical and effective ways of communicating the cruxes of the Errors to the other ED students because the weaknesses of instructing the cruxes of the errors were the uses of the adopted learning strategies and Traditional Assessment.

\section{References}

Al-Harbi, A. (2010). Mother tongue maintenance and second language sustenance: A two-way language teaching method. TESOL Journal, 2, 144-158.

Al-Khresheh, M. H. (2010). Interlingual Transfer in The English Language Word Order Structure of Jordnian EFL Learners. European Journal of Social Science, 16(1).

Azar, S. B. (1989). Understanding and Using English Grammar (2nd ed.). New Jersey: Prentice-Hall, Inc.

Bagaric, V., \& Djigunovic, M. J. (2007). Defining Communicative Competence. METODIKA, 8(14), 94-103. Retrieved from https://archive.org/stream/ERIC_ED529859/ERIC_ED529859_djvu.txt

Baker, M. (2009). In other Words - A Course Book on Translation. Beijing: Foreign Language Teaching and Research Press.

Bell, M. L., \& Aldridge, M. J. (2014). Student Voice, Teacher Action Research and Classroom Improvement. Rotterdam: Sense Publishers. https://doi.org/10.1007/978-94-6209-776-6

Bell, T. R. (1991). Translation and Translating: Theory and Practice. NY: Longman Inc.

Bickel, B. (2019). What is typology? — a short note. Retrieved May 6, 2019, from http://www.uni-leipzig.de 
Brinton, L. J., \& Donna, M. B. (2010). The linguistic structure of Modern English (2nd ed.). Amsterdam: John Benjamins Publishing Company. https://doi.org/10.1075/z.156

Brown, K., \& Miller, J. (2013). The Cambridge Dictionary of Linguistics. Cambridge: Cambridge University Press. https://doi.org/10.1017/CBO9781139049412

Bussmann, H. (1996). Routledge Dictionary of Language and Linguistics, London: Routledge, s.v. error analysis. A comprehensive bibliography was published by Bernd Spillner (1991), Error Analysis. Amsterdam/Philadelphia: Benjamins.

Chamot, U. A., Barnhardt, S., El-Dinary, B. P., \& Robbins, J. (1999). The Learning strategy Handbook. NY: Addison Wesley Longman, Inc.

Chelli, S. (2014). Interlingual or Intralingual Errors in The Use of Prepositions andArticles: A Case of First-Year Students of English at Biskra University. Algeria: University of M'Sila.

Comrie, B., et al. (2013). “Chapter Introduction.” WALS Online - Chapter Introduction. The World Atlas of Language Structures Online.

Corder, S. P. (1967). The significance of learner's errors. International Review of Applied Linguistics, 5(4), 161170.

Corder, S. P. (1971). Idiosyncratic dialects and error analysis. International Review of Applied Linguistics, 9(2), 147-160. https://doi.org/10.1515/iral.1971.9.2.147

Corder, S. P. (1973). Introducing Applied Linguistics. Penguin, Hannondsworth.

Corder, S. P. (1975). Error analysis, Interlanguage and second language acquisition (Survey Article). Language Teaching and Linguistics (Abstracts), 8, 201-218. https://doi.org/10.1017/S0261444800002822

Corder, S. P. (1981). Error Analysis and Interlanguage. Oxford University Press, Oxford.

Corder, S. P. (1983). A role for the mother tongue. In S. Gass \& L. Selinker (Eds), Language Transfer in Language Learning (pp. 85-97). Newbury House, Rowley, MA.

Crossman, A., \& Cole, L. N. (2018). Understanding Purposive Sampling: An Overview of the Method and Its Applications. Retrieved April 15, 2019, from https://www.thoughtco.com/purposive-sampling-3026727

Dodigovic, M. (2005). Artificial Intelligence in Second Language Learning: Raising Error Awareness. Frankfurt Lodge: Multilingual Matters. https://doi.org/10.21832/9781853598319

Fraenkel, R. J., \& Wallen, E. N. (2009). How to Design and Evaluate Research in Education (7th ed.). NY: The McGraw-Hill Companies, Inc.

Gell-Mann, M., \& Ruhlen, M. (October 18, 2011). The origin and evolution of word order. Proceedings of the National Academy of Sciences of the United States of America, 108(42). https://doi.org/10.1073/pnas.1113716108

Graham, D. (2019). Voiceover. Retrieved from http://davidgraham.co/blog/?page_id=27

Grammarist. (n.d). Redundancies. Retrieved from https:/grammarist.com/redundancies/

Hu, S. (2010). Context of Situation in Translation. Journal of Language Teaching and Research, 1(3), 324-326. https://doi.org/10.4304/jltr.1.3.324-326

Huddleston, R., \& Pullum, K. G. (2005). A Student's Introduction to English Grammar. Cambridge: Cambridge University Press. https://doi.org/10.1017/CBO9780511815515

Huddleston, R. (1984). Introduction to the grammar of English. Cambridge: Cambridge University Press. https://doi.org/10.1017/CBO9781139165785

Huebner; T., \& Ferguson, A. C. (1991). Crosscurrents in Second Language Acquisition and Linguistic Theories (p. 124). John Benjamins Publishing. https://doi.org/10.1075/lald.2

Jackson, H. (1987). The value of error analysis and its implications for teaching and therapy - with special reference to Panjabi learners. In J. Abudarhan (Ed.), Bilingualism and the Bilingual: An Interdisciplinary Approach to Pedagogical and Remedial Issues (pp. 100-111). Nelson for the National Foundation for Educational Research, Windsor and Philadelphia.

James, C. (1998). Errors in Language Learning and Use: Exploring Error Analysis. NY: Addison Wesley Longman Inc. 
James, C. (2013). Errors in Language Learning and Use: Exploring Error Analysis. NY: Routledge. https://doi.org/10.4324/9781315842912

James, R. H. (2010). The Linguistic Theory of Numerals. Cambridge: Cambridge University Press.

Kumar, B. C. (2009). Degrees of Comparison. Retrieved from https://www.weblearneng.com/the-degrees-of-comparison

Kurniawan, M. (2018). The Analysis of Interlingual and Intralingual Interference in Children's Literature Translation Project. A Journal of Culture, English Language, Teaching \& Literature, 18(2), 224-239. https://doi.org/10.24167/celt.v18i2.1177

Kurylowicz, J. (1962). Poniatie izomorfizma. Ocherki po lingvistike (3rd ed.). Moscow, The Great Soviet Encyclopedia, (1970-1979). 2010 The Gale Group, Inc. Retrieved from https://encyclopedia2.thefreedictionary.com/Isomorphism+of+Linguistic+Levels

Lado, R. (1957). Linguistics Across Cultures. University of Michigan Press, Ann Arbor, MI.

Larson, L. M. (1984). Meaning-based Translation: A Guide to Cross-Language Equivalence. Lanham LD: University press of America, Inc.

Lennon, P. (n.d). Contrastive Analysis, Error Analysis, Interlanguage. Retrieved from http://wwwhomes.uni-bielefeld.de/sgramley/CA-ErrorAnalysis-Interlang-Lennon.pdf

Menner, R. J. (1973). Hypercorrect forms in American English. American Speech, 12(3), 167-178. https://doi.org/10.2307/452423

Miles, M. B., \& Huberman, A. M. S. J. (1994). Qualitative Data Analysis A Methods Sourcebook of New Methods. California; SAGE publications Inc.

Moravcsik, E. (2013). Introducing Language Typology (p. 9). Cambridge, London: Cambridge University Press. https://doi.org/10.1017/CBO9780511978876

Mungungu, S. S. (2010). Error Analysis: Investigating the writing of ESL Namibian Learners. Unpublished Master's thesis, the University of South Africa, South Africa.

Muysken, P., \& Smith, N. (2008). The study of pidgin and creole languages. In J. Arends, P. Muijsken \& N. Smith (Eds.), Pidgins and Creoles: An Introduction (pp. 3-14). John Benjamins. https://doi.org/10.1075/cll.15.05muy

Nichol, M. (2019). 10 Types of Hypercorrection. Retrieved from https://www.dailywritingtips.com/10-types-of-hypercorrection/

Nordquist, R. (2019). Common Redundancies in the English Language. Retrieved from https://www.thoughtco.com/common-redundancies-in-english-1692776

O’Dwyer, B. (2000). Modern English Structures: Form, Function, and Position. Peterborough, Ontario: Broadview Press.

Pawlak, M. (2012). Error Correction in the Foreign Language Classroom: Reconsidering the Issues. NY: Springer-Verlag Berlin Heidelberg.

Rustipa, K. (2011). Contrastive Analysis, Error Analysis, Interlanguage and the Implication to Language Teaching. Ragam Jurnal Pengembangan Humaniora, 11(1), 16-22.

Sari, P. M. E. (2016). Interlingual Errors and Intralingual Errors Found in Narrative Text Written by EFL Students in Lampung. Jurnal Penelitian Humaniora, 17(2), 87-95. https://doi.org/10.23917/humaniora.v17i2.2501

Sattayatham, A., \& Honsa, S. (2007). Medical students' most frequent errors at Mahidol University, Thailand. Asian EFL Journal, 9(2), 170-194.

Sattayatham, A., \& Ratanapinyowong, P. (2008). Analysis of Errors in Paragraph Writing in English by First Year Medical Students from the Four Medical Schools at Mahidol University. Silpakorn University International Journal, 8, 17-38.

Selinker, L. (1969). Interlanguage, IRAL, 3, 114-132.

Selinker, L. (1972). Interlanguage. International Review of Applied Linguistics, 10(3), 209-231. https://doi.org/10.1515/iral.1972.10.1-4.209

Selinker, L. (1992). Rediscovering Interlanguage. Longman, London 
Sereebenjapol, P. (2003). An Analysis of the errors in English which graduate science students make in the discussion section of their thesis. Unpublished, Master's Thesis, Mahidol University, Thailand.

Shekhzadeh, E., \& Gheichi, M. (2011). An Account of Sources of Errors in Language Learners' Interlanguage. International Conference on Languages, Literature and Linguistics, IPEDR vol.26 IACSIT Press, Singapore.

Song, J. J. (ed.) (2011). The Oxford Handbook of Linguistic Typology. Oxford: Oxford University Press. https://doi.org/10.1093/oxfordhb/9780199281251.001.0001

Song, L. (2010). The Role of Context in Discourse Analysis. Journal of Language Teaching and Research, 1(6), 876-879. https://doi.org/10.4304/jltr.1.6.876-879

Teflnet. (1998-2019). TEFL Glossary. Retrieved from https://www.tefl.net/ref/glossary.htm

Touchie, Y. H. (1986). Second Language Learning Errors: Their Types, Causes, and Treatment. JALT Journal, $8(\mathrm{I}), 75-80$.

Unison, the Open University. (2019). Self-Reflection. $\quad$ Retrieved from http://www.open.ac.uk/choose/unison/develop/my-skills/self-reflection

Wells, J. C. (1982). Accents of English: An Introduction. Cambridge: Cambridge University Press.

William, L. (1972). Sociolinguistic Patterns (p. 126). University of Pennsylvania Press.

Wilson, K. G. (1993). The Columbia Guide to Standard American English. Columbia: Columbia University Press.

Wit, J. E., \& Gillette, M. (1999). What is Linguistic Redundancy? Retrieved from http://www.math.rug.nl/ ernst/linguistics/redundancy3

\section{Copyrights}

Copyright for this article is retained by the author, with first publication rights granted to the journal.

This is an open-access article distributed under the terms and conditions of the Creative Commons Attribution license (http://creativecommons.org/licenses/by/4.0/). 